\title{
ONOMÁVAIN
}

Revista de lingüística, filología y traducción

\section{A propósito de las imágenes esquemáticas presentes en la complementación nocional regida por el verbo salir}

On the image schemas in the notional complements selected by the verb to go out

\section{Elisa Barrajón López \\ Universidad de Alicante \\ España}

\section{(c) $($ i) $\odot$}

Elisa Barrajón López: Departamento de Filología Española, Lingüística General y Teoría de la Literatura, Facultad de Filosofía y Letras, Universidad de Alicante, España. | Correo electrónico: elisa.barrajon@ua.es 


\section{Resumen}

La metáfora y la metonimia son dos mecanismos de conceptualización básicos que permiten justificar los usos nocionales del verbo salir como casos de desviación semántica de su correspondiente complementación local. En este trabajo se demostrará que las estructuras abstractas seleccionadas por este verbo pueden explicarse a partir de la proyección de tres imágenes esquemáticas básicas: Ia imagen de trayectoria, la imagen de recipiente y la imagen parte-todo (con sus dos proyecciones metonímicas: el todo por la parte y la parte por el todo). No obstante, se estudiarán otras imágenes esquemáticas subsidiarias a las metáforas de recipiente y de trayectoria: la imagen esquemática de fuerza, la imagen esquemática de proceso, la imagen esquemática lleno-vacío y la imagen esquemática de exceso. Los ejemplos los he tomado de dos corpus orales - Corpus oral de la variedad juvenil universitaria del español hablado en Alicante (COVJA) ${ }^{1}$ y Alicante, Corpus del español (ALCORE) ${ }^{2}$-, en los que he observado un uso frecuente de estas estructuras; y de un corpus escrito - CREA-, al que he recurrido con el fin de obtener una base de datos más amplia.

Palabras clave: imágenes esquemáticas; metáfora; metonimia; trayectoria; recipiente.

\section{Abstract}

Metaphor and metonymy are two mecanisms of basic conceptualization that justify the notional uses the verb motion go out as semantically derived from its corresponding prototypical uses. In this paper we will demonstrate that the abstract structures involving this verb can be explained by the projection of three basic image schemas: the path schema, the

$1 \quad$ Esta obra responde a un proyecto de investigación subvencionado por el Instituto de Cultura Juan Gil-Albert y coordinado por la Dra. Dolores Azorín Fernández y el Dr. Juan Luis Jiménez Ruiz. En la elaboración de este corpus han participado profesores del Área de Lengua Española de la Universidad de Alicante, entre los cuales me incluyo.

2 Este trabajo se enmarca dentro del proyecto ALCORE, subvencionado por el Ministerio de Educación y Cultura y coordinado por la Dra. Dolores Azorín Fernández. Su principal objetivo fue la plasmación en un corpus del estado actual de la lengua oral utilizada en diferentes barrios de la ciudad de Alicante. 
container schema and the whole-part schema (with its two metonymical directions: whole by part and part by whole). However, we will study others subsidiary image schemas of container and path metaphors: the force image schema, the process image schema, the fullempty image schema and the excess image schema. The examples were drawn from two oral corpora-Corpus oral de la variedad juvenil universitaria del español hablado en Alicante (COVJA) y Alicante, Corpus del español (ALCORE) -, where I have noticed a frequent use of these structures; and from one corpus written-CREA-, to which I have resorted in order to get a broaden database.

Keywords: image schema; metaphor; metonymy; path; container. 


\section{Introducción}

El verbo de desplazamiento salir expresa el cambio de lugar que experimenta el sujeto como resultado de un movimiento. El sujeto abandona el lugar en que se encontraba en el momento previo al desplazamiento para situarse en una nueva localización o ubicación. Por ello, esta unidad verbal implica una superación de un límite espacial: la acción descrita "se inicia en el interior del objeto de referencia y termina en su exterior" (Morimoto, 2001: 88). Salir es, además, un verbo direccional, es decir, cuenta con una orientación inicial intrínseca, dado que polariza el lugar inicial que sirve de punto de referencia al desplazamiento y que puede ser entendido como 'origen' o 'fuente del movimiento's. No obstante, esa incidencia espacial inicial inherente no excluye el estado final del proceso de movimiento. Así, siguiendo a Boons (1987: 18), podríamos definir salir como un verbo complejo o "bipolar inicial" que, si bien incide en el estado inicial del proceso (Pedro salió de casa), no niega en ningún momento la fase final del mismo (Pedro salió a la calle)4. Por lo tanto, salir, como verbo de desplazamiento direccional, implica las tres fases propias de todo verbo de desplazamiento (inicial, proceso y final), aunque sólo las fases inicial y final se lexicalizan mediante un complemento locativo argumental, pudiendo aparecer explícita solamente una de ellas en un mismo enunciado (*Pedro salió de casa a la calle), mientras que la otra quedaría latente.

Tomando como base la estructura del movimiento, propuesta por Talmy (1975: 182), junto con sus componentes cognitivo-semánticos fundamentales (Figura, Base o Fondo, Trayectoria y Movimiento), se puede señalar que el componente figura - "objeto que se desplaza o que es localizado en relación con otro objeto" (Crego, 2000: 25)-, en el caso de un verbo intransitivo como salir, es, normalmente, el 'agente's del movimiento; mientras que la base ${ }^{6}$ se realiza sintácticamente mediante un complemento locativo subcategorizado. Por lo que respecta al componente trayectoria, este se formaliza a través de un elemento prepositivo direccional (Laur, 1993: 50) que, dependiendo de la orientación del movimiento (inicial o final) descrita, podrá ser la preposición de o la preposición a.

3 Esta polaridad inicial es lo que ha llevado a algunos autores a clasificarlo como predicado de desplazamiento "ablativo" (Horno, 2002: 365).

4 Sobre la posibilidad de salir de concretar el destino del movimiento puede verse Verveckken y Delbecque (2007).

5 Comparto la opinión de Cifuentes Honrubia acerca de que no existen en español y en catalán, a diferencia de otras lenguas como el italiano, pruebas sintácticas concluyentes que permitan determinar el carácter inacusativo de los verbos de movimiento intransitivos como salir (1999: 39).

6 En este trabajo, el término base será usado en un sentido amplio, dado que no sólo aludirá a entidades físicas, sino también a entidades inmateriales o abstractas (Cifuentes y Llopis, 1996: 27-28). 
La direccionalidad supone un recorrido horizontal cuyos ejes o parámetros son tres: origen, meta o destino y trayectoria. El rasgo [+dirección] puede expresarse tanto a través de la unidad verbal - hablaríamos, entonces, de una direccionalidad intrínseca- como de los complementos locativos argumentales que le acompañan -estaríamos ante una direccionalidad extrínseca - (Crego, 2000: 106). En ese último caso, la direccionalidad extrínseca se serviría de los elementos prepositivos (de o a) para marcar el origen o el destino.

Sin embargo, el verbo salir no solamente requiere complementos preposicionales de naturaleza física o espacial, sino que, frecuentemente, la complementación que lo acompaña responde a sentidos figurados o abstractos. En estos casos, el verbo salir se desprende de sus semas de [movimiento] y [desplazamiento] ${ }^{7}$ y, por tanto, no existe una relación locativa en sentido estricto entre una entidad desplazada y un elemento espacializador que señala su ubicación inicial. El proceso de abstracción sufrido por estas estructuras nos lleva a interpretar la base de localización como un lugar abstracto del que no se sale literalmente, sino metafóricamente. En el ámbito nocional, los complementos nucleares exigidos por salir no remiten a lugares perfectamente delimitados y tangibles, a superficies concretas y medibles, sino a entidades abstractas, figuradas o imprecisas que concebimos como espacios cerrados o abiertos con un interior y un exterior.

En algunos estudios (Boons, 1985; Lamiroy, 1991; García-Miguel, 1995; Crego, 1996 y 2000), los complementos regidos nocionales de los verbos de movimiento han sido contemplados como un caso de desviación semántica o metafórica de su correspondiente complementación local. Esto supone que la ausencia de contenidos estrictamente espaciales no siempre es síntoma de una configuración sintáctica diferente.

El ser humano conceptualiza estas relaciones abstractas y las situaciones complejas que implican partiendo de estructuras básicas, pertenecientes al ámbito local, las cuales le resultan más conocidas por su constante contacto con el espacio y con los objetos que lo conforman. Este proceso cognitivo constituye la base de toda proyección metafórica, dado que la metáfora "constituye un mecanismo para comprender y expresar situaciones complejas sirviéndose de conceptos más básicos y conocidos” (Lakoff y Johnson, 1991: 99). Por ello, la metáfora opera entre dos dominios conceptuales - el dominio origen (el espacio y los elementos que lo configuran) y el dominio destino (estructuras nocionales definidas a partir de

7 Si considero el 'desplazamiento' como uno de los semas básicos del verbo salir es debido a que, si el sujeto sale de algún lugar, ese sujeto no sólo cambia de lugar, sino que, al pasar de un sitio a otro, se desplaza, se mueve del lugar en el que se encuentra inicialmente. Por tanto, sin desplazamiento no puede haber un cambio de ubicación. Lo mismo ocurre en contextos no locales, en los que las entidades se desplazan figurativamente desde un punto inicial hasta un destino, tal como se verá al abordar el esquema de trayectoria. 
conceptos básicos del dominio origen)-, estableciendo una serie de correspondencias que enlazan ambos dominios. Sin embargo, es conveniente subrayar que estas correspondencias no son totales, sino parciales, pues no proyectamos toda la información de un dominio sobre otro, sino solamente parte de ella. De ahí que la metáfora se sirva de imágenes esquemáticas que responden a representaciones parciales e idealizadas de la realidad extralingüística y que nos permiten reconocer similitudes entre el ámbito espacial (dominio bien delimitado en nuestra experiencia cotidiana) y nocional (dominio menos accesible para nuestra comprensión). Seguimos, por tanto, un patrón de direccionalidad, que avanza de lo concreto y más accesible a lo abstracto y de difícil comprensión (Taylor, 1989: 138; Sweetser, 1990: 18; Geeraerts y Cuyckens, 2007: 28).

Por su parte, la metonimia es un mecanismo cognitivo y, en muchos casos, referencial ${ }^{8}$ (Lakoff y Johnson, 1991: 74) que relaciona dos entidades pertenecientes al mismo dominio denominado por Barcelona "dominio funcional" (2012: 127-128)—, remitiendo a una entidad implícita mediante otra explícita y "conectados por una función pragmática” (Barcelona, 2012: 126). Tal como ocurre con la metáfora, la metonimia también se sirve de imágenes esquemáticas que nos permiten comprender las correspondencias establecidas entre dichas entidades.

La metáfora y la metonimia, como sistemas de conceptualización fundamentados en la generación de imágenes esquemáticas, serán las herramientas cognitivas de las que partiré en el estudio de la complementación nocional seleccionada por el verbo salir que pretendo llevar a cabo en este trabajo Así, los usos no locales que presenta este lexema verbal pueden justificarse a través de la proyección de tres imágenes esquemáticas conceptuales básicas: el esquema de trayectoria, el esquema de recipiente y el esquema de parte-todo. Los ejemplos analizados 9 han sido extraídos de tres corpus: dos de carácter oral -Corpus oral de la variedad juvenil universitaria del español hablado en Alicante (COVJA) y Alicante, Corpus del español (ALCORE) - y uno escrito —Corpus de la Real Academia Española (CREA)—.

\section{Imagen esquemática de trayectoria}

Toda imagen esquemática está provista de una estructura interna lógica constituida por varios elementos estructurales que permiten la proyección metafórica de un dominio concreto

8 Soy consciente de que la metonimia no siempre es referencial (Barcelona, 2002 y 2012), aunque en los ejemplos que he manejado sí que responde a un mecanismo referencial.

9 El estudio que presento aquí es una pequeña muestra representativa de lo que en su momento fue el tema de mi tesis doctoral, en la que se analizaron cuatrocientos ejemplos con este verbo de movimiento. 
a otro abstracto (Evans y Green, 2006: 185). El esquema conceptual de trayectoria responde a la siguiente estructura interna, que se ajusta a la conceptualización que realizamos del verbo salir:

- Un “landmark” (Langacker, 1990: 6), que en este caso se trata de una 'fuente' o 'punto de partida’ que corresponde a la 'localización inicial abstracta’ (lugar nocional o entidad humana) ${ }^{10}$.

- Un 'destino' o 'punto final' que, en la mayoría de las construcciones que nos ocupan, no se concreta.

- Una ‘direccionalidad' u 'orientación’ inherente, marcada por el elemento prepositivo ('eferencialidad').

- Un "trajector" (Langacker, 1990: 6) o figura que se desplaza. Puede tener un carácter humano o inanimado.

- Una ruta o recorrido que se extiende desde la 'fuente' hasta la 'meta'.

- Posición o ubicación inicial de la figura desplazada.

El movimiento a lo largo de una trayectoria procedente de nuestra experiencia física cotidiana nos ayuda a conceptualizar situaciones abstractas en las que los participantes se desplazan figurativamente desde un 'punto inicial' hasta un 'destino' situado al final de la trayectoria. Se trata, por tanto, de una trayectoria dinámica y horizontal que puede ser representada de la siguiente manera ${ }^{11}$ :

\section{FIGURA 1}

Representación del esquema conceptual de trayectoria



Para entender mejor este esquema conceptual, expondré algunos ejemplos:

10 Esta localización inicial puede entenderse al mismo tiempo como una 'localización trasera', mientras que el ‘destino' o ‘punto de llegada' correspondería a la posición delantera. Este es el motivo por el que sobre este esquema conceptual de trayectoria puede también proyectarse la imagen esquemática subsidiaria “delante-detrás" (Peña, 2003: 180; Peña y Ruiz de Mendoza, 2010: 270).

11 La flecha marcada mediante puntos indica que con este esquema de trayectoria lo que se focaliza especialmente es el origen o la fuente del desplazamiento más que la meta o el destino final. 
(1) [...] Ten en cuenta que salimos de una guerra y luego una posguerra. [...] (ALCORE, 2002: 344).

(2) [...] Quien ha estado en la droga, ¿puede salir de la droga? [...] (CREA).

(3) Sus trabajos nos muestran cómo puede salir de una máquina no una simple fotografía sino una obra de arte; [...] (CREA).

En todos estos casos, la figura es una entidad humana o inanimada (4) que se desplaza a través de una trayectoria horizontal con un destino no concretado, dado que lo que se pone de relieve en estas estructuras es la 'eferencialidad nocional' marcada por la preposición de que introduce el complemento que expresa la 'ubicación inicial'. El punto de partida viene representado por entidades abstractas de diferente tipo: referentes a sucesos bélicos (una guerra, una posguerra), a situaciones conflictivas (la droga), etc.

Junto a esa imagen esquemática básica de trayectoria, podemos encontrar otras subsidiarias o dependientes que la enriquecen y amplían su estructura general (Peña, 1998, 2008 y 2012²; Peña y Ruiz de Mendoza, 2010: 270), estableciéndose así una relación jerárquica entre ellas y produciéndose un enriquecimiento esquemático (Peña, 1998: 422-423 y 2003: 214).

La primera imagen esquemática subsidiaria al esquema conceptual de trayectoria es la imagen esquemática de fuerza (Johnson, 1987: 126). Si la figura realiza un movimiento a lo largo de una trayectoria, puede que exista una causa o una fuerza que motive su desplazamiento (Talmy, 2000: 413). A este tipo de fuerza se la ha denominado "compulsión" (Johnson, 1987: 126; Peña, 2003: 146 y 2004: 140; Peña y Ruiz de Mendoza, 2010: 270). Si bien el verbo salir no ha sido definido como un verbo causativo, podemos entender, en algunos casos, la presencia de una fuerza que motiva o que influye en una entidad para actualizar el sema [desplazamiento] que contiene este lexema verbal:

\section{FIGURA 2}

Representación del esquema conceptual de compulsión

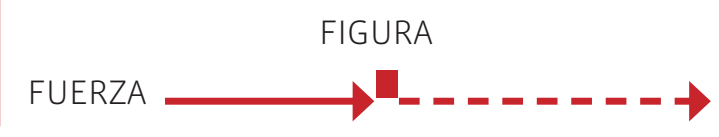

Veamos los siguientes ejemplos:

12 Peña Cervel rechaza el planteamiento de Johnson según el cual todas las imágenes estarían situadas al mismo nivel. Esta misma idea ya la encontramos en el trabajo de Chamizo (1998: 53). 
(4) [...] Y antes de despedirse ${ }^{13}$, apostilló: "Conmigo o sin mí, pero la Real va a salir de esos puestos de cola en los que se encuentra ahora. [...] (CREA).

(5) La función del siquiatra no es la de "normalizar", sino tratar de dar al paciente [...] Una capacidad de salir de su aislamiento $y$ [...] (CREA).

En estos dos ejemplos podemos atribuirle a una entidad humana (Julio César, el psiquiatra) el papel de fuerza que ejerce su control sobre una entidad (la Real, el paciente), para alejarla, a su vez, de situaciones perjudiciales para ella (esos puestos de cola, su aislamiento), por lo que también parece intervenir otro tipo de fuerza: "repulsión" (Johnson, 1987: 127; Peña, 2003: 165; Peña y Ruiz de Mendoza, 2010: 270), subsidiaria de la que estamos comentando (“compulsión”). La figura abandona una situación o ubicación inicial que le perjudica. Por tanto, su desplazamiento tiene, en estos casos, repercusiones positivas para ella (Peña, 2003: 278).

En otras ocasiones, la fuerza presenta un carácter inanimado, pero eso no impide que desencadene el desplazamiento de la figura en cuestión:

(6) [...] El teatro te da la posibilidad de salir de ti mismo [...] (CREA).

(7) [...] la "intuición sentimental directa" que nos ayuda a descubrir al otro, a salir de nosotros mismos y liberarnos [...] (CREA).

Así, ciertas circunstancias cotidianas, como el teatro o la intuición sentimental directa, pueden empujar a determinadas entidades humanas a iniciar un desplazamiento figurativo. En los ejemplos (6) y (7), la presencia de expresiones como da la posibilidad, ayuda a, subrayan la existencia de esa fuerza.

Por último, la fuerza no necesariamente tiene que estar explícita, sino que puede entenderse implícitamente, es decir, se presupone la actuación de algo que motiva el desplazamiento, aunque no se concrete:

(8) [...] he tenido que reflexionar mucho y salir de mí y planteármelo [...] (CREA).

La presencia de la perífrasis de obligación tener que nos induce a pensar, siguiendo a Talmy (2000: 449-452), que en este ejemplo existe algo que motiva el abandono de la figura de una localización inicial de carácter nocional.

13 Se refiere a Julio César, jugador de la Real Sociedad. 
La figura también puede encontrar en su recorrido algún obstáculo que le impida conseguir sus propósitos, de tal manera que dificulta su progreso y no es capaz de alcanzar su destino. A este tipo de fuerza se la denomina “bloqueo" (Johnson, 1987: 126; Lakoff y Johnson, 1999: 189; Talmy, 2000: 458; Peña, 2003: 149):

\section{FIGURA 3}

Representación del esquema conceptual de Bloqueo

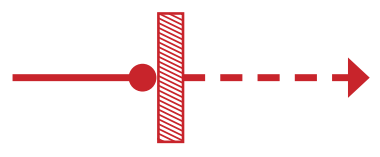

De nuevo, esa fuerza obstructora puede aparecer explícita —-(9) - o implícita —(10)—:

(9) Su mentalidad era un obstáculo para un mundo que ya pugnaba por salir de la edad me$\operatorname{dia}[\ldots](C R E A)$.

(10) La segunda era ver si el presidente era capaz de salir de esa crisis con alguna recuperación de fuerza, y no ha sido así (CREA).

En (10) se entiende que ha habido algo que ha obstaculizado el progreso en ese desplazamiento figurativo del presidente, por lo que no ha conseguido alejarse de esa crisis entendida como lugar nocional. De ahí que otro de los factores a tener en cuenta en estos casos sea la intensidad (más fuerte o más débil) obstructora del "antagonista” (Talmy, 2000: 414).

Sin embargo, a veces, la fuerza que impide que la entidad desplazada pueda llevar a cabo su movimiento a lo largo de la trayectoria desaparece. Es lo que se conoce como la eliminación de la entidad que restringe el movimiento, es decir, la eliminación de barreras (Johnson, 1987: 126; Peña 2003: 156 y 2004: 144). De esta forma, las entidades desplazadas son capaces de moverse y recuperar su capacidad para llevar a cabo ese desplazamiento, ya que no existe ningún obstáculo que imposibilite el progreso de la figura a lo largo de la trayectoria y logra alcanzar su meta:

(11) Seat ha logrado salir de las pérdidas que arrastraba [...] (CREA).

Otra de las imágenes esquemáticas dependientes de la metáfora de trayectoria es la llamada imagen esquemática de proceso (Johnson, 1987: 126; Peña, 2003: 177). Una de las realizaciones específicas de este esquema es la que constituye la metáfora conceptual14 UN CAMBIO DE ES-

14 Parto de la distinción de Lakoff y Johnson entre "metáforas conceptuales" y "expresiones metafóricas" (1991: 43). 
TADO ES UN CAMBIO DE LOCALIZACIÓN. Sobre esa metáfora general puede establecerse otra más concreta que es la de UN CAMBIO DE ESTADO ES UN CAMBIO DE TRAYECTORIA, ya que una nueva trayectoria supone una nueva localización. A esta metáfora conceptual pueden ajustarse las siguientes expresiones metafóricas presentes en los corpus de ejemplos manejados:

(12) [...] ello puede ayudar a la sociedad española a salir de esa amnesia, [...] (CREA).

(13) Las autoridades se han visto obligadas en esta ocasión a salir de su mutismo habitual e informar de la matanza [...] (CREA).

En (12) y (13), el punto de partida inicial constituye un estado en el que se encuentra la figura (amnesia, mutismo) momentos antes de iniciar el desplazamiento. De manera que el alejamiento de ese estado supone también un cambio en su ubicación, así como la meta alcanzada implica la adquisición de otro estado distinto.

La imagen esquemática de trayectoria es una de las metáforas más básicas que pueden explicar nuestro modo de conceptualizar y de entender la combinatoria del verbo salir con complementaciones de carácter nocional procedentes de complementos locales. Así, proyectamos determinados elementos (trayectoria, direccionalidad, localización inicial, meta o destino, figura desplazada, etc.) que estructuran y conforman nuestra experiencia física en términos de trayectoria hacia otras entidades cuya complejidad y abstracción requieren un procesamiento y captación mayores. De manera que la metáfora lleva impresa una direccionalidad concreta que avanza de lo físico a lo no físico, de lo concreto a lo abstracto, de lo local a lo metafórico.

\section{Imagen esquemática de recipiente}

La imagen esquemática de recipiente es otra de las metáforas básicas que interactúa junto con la imagen de trayectoria y que, por tanto, contribuye al enriquecimiento de la estructura lógica interna básica del esquema de trayectoria15.

La imagen esquemática de recipiente, como la metáfora de trayectoria, cuenta con una serie de elementos que configuran su estructura interna. Estos elementos son:

15 Aunque no existe en estos casos ningún elemento que aluda explícitamente al esquema conceptual de recipiente, considero que esta imagen se encuentra al mismo nivel que la de trayectoria, dado que la localización inicial del trayector puede entenderse también como un contenedor. De manera que uno puede salir figurativamente de una situación, estado o condición de la misma manera que puede abandonar una región limitada en el espacio (Peña, 2003: 64). 
- Un interior limitado vacío o lleno. Si está lleno, las entidades encontradas en su interior (personas o cosas) pueden afectar al recipiente positiva o negativamente (Johnson, 1987: 987; Lakoff, 1987; Fornés y Ruiz de Mendoza, 1998; Peña, 2003 y 2004). Al mismo tiempo, el contenedor puede proteger a las entidades que contiene de todo aquello del exterior que resulte perjudicial o privarlas de lo que pueda beneficiarlas. Las entidades contenidas en el recipiente pueden verse afectadas positivamente, si el contenido del recipiente es positivo, o negativamente, si su contenido es negativo.

- Un exterior al que se dirige la entidad que se desplaza.

El recipiente puede estar abierto o cerrado. Atendiendo a los ejemplos analizados, en la mayoría de ocasiones, el recipiente estará abierto. De esta manera, el contenedor no impide el movimiento de las entidades que se encuentran en su interior. Además, estas entidades pueden salir de la región limitada que supone el recipiente para no ser controladas por él (Peña, 2003: 92). Los contenedores crean un área de influencia que les permite controlar las entidades que hay en su interior. Si la figura está fuera del landmark no podrá ser controlado por él, estará fuera de su zona de influencia. Por ello, cuanto más cercano esté del landmark, más control ejercerá este sobre la figura. El componente control decrece en función de la distancia física.

En un recipiente podemos encontrar dos tipos de entidades cognitivas básicas: cosas y personas (Peña, 2003: 59 y 2004: 130). Comentaré, en primer lugar, los casos en los que las entidades que conforman el recipiente son de carácter abstracto y pueden dar lugar a diferentes metáforas conceptuales.

A partir de la imagen esquemática de recipiente, una de las metáforas conceptuales a las que se ajustan los ejemplos manejados es la de EL TIEMPO O UNA ETAPA TEMPORAL ES UN RECIPIENTE (Lakoff y Johnson, 1991: 99):

\section{(14) [...] que si estamos saliendo de la eda<(d)> del pavo [...] (COVJA, 1999: 72).}

(15) Su mentalidad era un obstáculo para un mundo que ya pugnaba por salir de la edad media $[\ldots](C R E A)$.

En estos dos ejemplos, la preposición de marca el 'punto de referencia inicial' (la edad del pavo, la edad media) en el que se encuentra la figura (nosotros, un mundo) momentos antes de comenzar su desplazamiento. Dado que el contenido del recipiente presenta un valor negativo, el abandono o el intento de abandono del recipiente por parte de la figura, alejándose con ello de su área de influencia negativa, tiene repercusiones positivas para ella. En estos tres casos, como vemos, el recipiente está abierto y no actúa como barrera al movimiento de la figura: 


\section{FIGURA 4}

Representación del recipiente abierto



Otra de las metáforas conceptuales que es posible establecer a partir de los ejemplos encontrados es la de LAS DOCTRINAS POLÍTICAS SON RECIPIENTES:

(16) [...] había que salir de la camiseta estrecha del franquismo [...] (CREA).

(17) [...] "Este era un país", dijo, "que quería salir de la dictadura [...] (CREA).

La localización inicial alude a entidades abstractas referentes al mundo de la política que reciben una connotación claramente negativa, por lo que las entidades contenidas en el recipiente, en estos casos, lo afectan negativamente. La figura, de carácter humano o inanimado, se desplaza para abandonar la región limitada constituida por el recipiente y liberarse así de su contenido negativo.

La siguiente metáfora conceptual que puede señalarse es la de LOS ESTADOS SON RECIPIENTES (Lakoff y Johnson, 1991: 70), de la que pueden citarse las siguientes expresiones metafóricas:

(18) El país no termina de salir de su asombro por lo ocurrido [...] (CREA).

(19) LAS ELECTRICAS no acaban de salir de la fase de relativa debilidad en la que se encuentran desde hace dos o tres semanas [...] (CREA).

La idea de recipiente se acentúa especialmente en aquellos casos en los que la figura permanece en su interior. En el ejemplo (19) la presencia de la oración de relativo introducida por la preposición estativa en, que alude a las nociones de 'interioridad' y de 'límites cerrados' (Morera, 1988: 361), contribuye a enfatizar la imagen de recipiente. El contenido del recipiente puede entenderse como un estado en el que se encuentra el sujeto mientras permanece en su interior. De ahí que anteriormente haya relacionado estos ejemplos con la imagen esquemática de proceso subsidiaria de la de trayectoria, según la cual un cambio de estado supone un cambio de localización.

Dentro de la metáfora conceptual que estoy comentando se puede ubicar otra más específica que es la de LOS ESTADOS EMOCIONALES O LAS EMOCIONES SON RECIPIENTES (Peña, 2003: 64): 
(20) [...] "todavía está saliendo de la depresión y que mejor obviar el tema [...] (CREA).

(21) [...] María Eugenia acaba de salir de una relación [...] (CREA).

Las depresiones y las relaciones amorosas pueden entenderse como estados emocionales a los que podemos dotar de una superficie determinada, como si de un objeto se tratase. De esa manera podemos salir y entrar en ellas, como si fueran recipientes con un interior y un exterior. Les asignamos la misma orientación dentro-fuera que proyectamos sobre cualquier objeto físico de nuestra experiencia. Esta tendencia se debe, según Lakoff y Johnson, a nuestro instinto humano de la territorialidad y de imponer límites para señalar nuestro territorio de manera que cuente con un interior y con una superficie que lo limite (1991: 68).

Una de las metáforas conceptuales más frecuentes en el corpus de ejemplos manejado y que está relacionada con el esquema de recipiente es la de LAS SITUACIONES CONFLICTIVAS O PROBLEMÁTICAS SON RECIPIENTES (Radulescu, 2005: 899):

(22) [...] le vendrá muy bien a Neo para salir de los peores enredos (CREA).

(23) [...] Por quienes aspiran a salir de este gran bache [...] (CREA).

En todos estos casos, la ubicación inicial remite a situaciones conflictivas (enredos, un bache) de las que la figura intenta alejarse debido a su alto contenido negativo. Se trata de circunstancias que preocupan o molestan y que requieren un notable esfuerzo por parte del sujeto a la hora de controlarlas.

El recipiente puede estar lleno o vacío. En todos los casos anteriores el recipiente estaba Ileno y su contenido era frecuentemente negativo. Por ello, junto a la imagen esquemática central de recipiente, pueden interactuar otras más secundarias, como la imagen esquemática lleno-vacío. A veces, el recipiente resulta demasiado limitado para albergar a todas las entidades que se encuentran en su interior. Ese parece ser el motivo que impulsa a la figura a abandonar el recipiente y a salir de su área de influencia. De esta manera, la figura ejerce presión sobre el recipiente y, aunque no lo destruye, sí que lo desborda. Es posible relacionar este hecho con la imagen esquemática de exceso (Peña, 2003: 116 y 2012: 876; Cifuentes Pérez, 2004: 304; Peña y Ruiz de Mendoza, 2010: 270) en el sentido de que el recipiente podría estar demasiado lleno y no tener capacidad suficiente para que la figura permanezca en su interior.

16 Aunque Peña Cervel reserva este esquema conceptual para aquellos casos en los que las personas son conceptualizadas como recipientes para contener las emociones, creo que también puede aplicarse cuando las entidades abstractas interpretadas como contenedores están al límite en términos de contenido y la figura tiene dificultades para encontrar su lugar en el interior del recipiente. 
De esta manera, el control que ejerce el recipiente sobre ella, así como la influencia de las entidades interiores, desaparecen totalmente. Esta imagen esquemática se ve reforzada por la estructura pronominal a la que responden las siguientes construcciones:

(24) Cierto que se trata de música excelente, pero tal vez se sale de lo que ha pretendido ser la obra. [...] (CREA).

En el interior del recipiente también existe la posibilidad de encontrar personas, dando lugar así a la metáfora conceptual LAS PERSONAS SON RECIPIENTES (Kövecses, 2000, 2006 y 2010; Peña, 2003: 68):

(25) [...] de padres buenos también salen hijos malos [...] (ALCORE, 2002: 1177).

(26) [...] saliendo de Fraga Iribarne, [...] (CREA).

En definitiva, las imágenes esquemáticas de trayectoria y de recipiente desempeñan un papel fundamental en la configuración de una serie de metáforas conceptuales que nos ayudan no sólo a entender las complementaciones preposicionales nocionales de salir en términos espaciales, sino también a ubicarlas en el mismo espacio funcional que las estructuras rectas, como subtipos de los empleos propios del lexema verbal en cuestión (Lamiroy, 1987: 55). Sin embargo, no son las únicas que interactúan en estas estructuras. Es conveniente también resaltar la importancia de otra imagen esquemática de la que se sirve, en este caso, la metonimia, para explicar conceptos complejos a través de otros más familiares y relevantes de la experiencia física: el esquema parte-todo.

\section{Imagen esquemática parte-todo}

El esquema conceptual parte-todo constituye la base de cualquier proyección metonímica. La metonimia es un mecanismo a menudo referencial (Barcelona, 2002 y 2012), es decir, "un tipo de referencia indirecta por la que aludimos a una entidad implícita 'zona activa' (Langacker, 1984 y 1990) a través de otra explícita 'punto de referencia' " (Langacker, 1993: 30)17. Por ello, su principal diferencia con respecto a la metáfora es que, si bien esta opera entre dominios diferentes, la metonimia opera dentro de un mismo dominio (Lakoff y Turner, 1989: 105), denominado por algunos autores “dominio funcional” (Barcelona, 2012: 127).

17 Entiendo, por tanto, el "punto de referencia" como aquella entidad explícita de la que nos servimos para establecer una conexión mental con otra perteneciente al mismo dominio nocional que permanece implícita. 
Dentro de este esquema conceptual parte-todo, la proyección metonímica puede realizarse en dos direcciones: o bien se toma el todo por la parte, esto es, se focaliza el todo para comprender su relación con una de sus partes ${ }^{18}$; o bien, la parte por el todo, es decir, se enfatiza una parte del dominio origen que es relevante para entender la expresión metafórica en cuestión.

\subsection{El todo por la parte}

Hay ocasiones en las que se enfatiza el todo para llegar a una de sus partes. En las ocurrencias analizadas, el esquema conceptual metonímico el todo por la parte supone, en muchos casos, la referencia explícita de un lugar para aludir implícitamente a la actividad desarrollada en dicho lugar. Intentaré analizar este proceso referencial mediante el siguiente ejemplo:

(27) [...] Y a los doce años ya me salí del colegio [...] (ALCORE, 2002: 1530).

El "punto de referencia" que actúa como todo (el colegio) constituye un lugar físico que remite implícitamente a una "zona activa"19 concreta: Ios estudios cursados en una institución docente. Por tanto, no es que la figura realice un desplazamiento físico a partir de un 'punto inicial' de carácter local, sino que se mueve figurativamente recorriendo una trayectoria que parte de un ámbito nocional: el ámbito académico. Además, en este ejemplo se pone de manifiesto la presencia de una fuerza no explícita que obliga a la figura a iniciar su movimiento. De tal manera que, junto con la metonimia señalada, interactúa la proyección metafórica del esquema conceptual de trayectoria, que se ve enriquecida al mismo tiempo por la imagen esquemática de fuerza.

No obstante, la imagen de recipiente también está presente en estas estructuras con una pequeña variación con respecto a las construcciones anteriores: del recipiente sólo tomamos una parte (la enseñanza) a la que dotamos de una superficie delimitada.

Este mismo planteamiento parece funcionar en otras estructuras en las que el complemento preposicional regido va introducido por la preposición a, aunque, en lugar de aludir a una actividad, se hace referencia a una acción. El sujeto no abandona un lugar

18 Denominadas por Antonio Barcelona (2011) "metonimias periféricas" o "puramente esquemáticas".

19 El concepto de "zona activa" debe entenderse, por ello, como el referente implícito al que pretendemos acceder mentalmente mediante una entidad explícita perteneciente al mismo dominio nocional. 
para dirigirse a otro ni el complemento introducido por la preposición a expresa el 'punto final del movimiento', ya que dicho complemento no constituye en estos casos la base de localización que dota al sujeto de una nueva ubicación. Solamente se hace hincapié en la acción en sí misma, en el acto de salir, de realizar una determinada actividad de ocio para disfrutar del tiempo libre:

(28) [...] disfrutar del nene salir a la playa, dormir [...] (ALCORE, 2002: 1150).

En este caso, la imagen de recipiente desaparece. No se focaliza ningún interior, sino el desarrollo de una acción que tiene lugar en el "punto de referencia" que se toma como base para llegar hasta el referente implícito. Además, el sustantivo que aparece como núcleo del sintagma prepositivo no puede interpretarse como un lugar en sentido estricto, por lo que también desaparecería el esquema conceptual de trayectoria: no existe un punto de partida ni tampoco una meta o un destino.

Finalmente, el todo puede referirse a una entidad animada de la que sólo nos interesa una parte, en este caso, un miembro de su cuerpo:

(29) [...] el macho se hinche, y de esta manera no pueda salir de la hembra [...] (CREA).

En este ejemplo, entiendo que mediante el "punto de referencia" (hembra) se alude a una "zona activa" que viene dada por el contexto situacional: vagina. Este punto de referencia puede interpretarse como recipiente, aunque focalizamos una parte del cuerpo como contenedor. Por otra parte, juega un papel fundamental una de las imágenes esquemáticas de trayectoria: el esquema conceptual de fuerza. En su trayectoria, la figura tropieza con un obstáculo (la hinchazón) que le impide realizar el movimiento.

\subsection{La parte por el todo}

La metonimia, como mecanismo preferentemente referencial, puede ser analizada desde otro punto de vista inverso al comentado en el apartado anterior. A diferencia de la proyección metafórica que siempre es unidireccional, esto es, avanza de lo concreto a lo abstracto, operando entre dos dominios cognitivos, la metonimia es bidireccional, avanza del todo a la parte o de la parte al todo, en el interior de un único dominio. En este apartado me centraré en el esquema conceptual metonímico la parte por el todo que, a su vez, puede verse enriquecido por diferentes imágenes esquemáticas con las que opera la metáfora.

La parte ("punto de referencia") que se toma como base para comprender el todo puede referirse a diferentes elementos de la realidad extralingüística. Uno de los más frecuentes 
en las ocurrencias manejadas es el de actividades y acciones de la vida cotidiana mediante las cuales se alude implícitamente a los lugares en los que dichas acciones se llevan a cabo y cobran su razón de ser. A este esquema conceptual, correspondiente a LA ACTIVIDAD O LA ACCIÓN POR EL LUGAR EN QUE SE DESARROLLA, pertenecen los siguientes ejemplos:

(30) [...] salga usted del examen, [...] (ALCORE, 2002: 900).

(31) [...] recuerda que Alejandro Dumas, al salir de su primera corrida, [...] (CREA).

(32) [...] Porque vas, sales de comer, de beber [...] (ALCORE, 2002 1673).

Como vemos, a través de determinados sustantivos (examen, corrida) e infinitivos (comer, beber), aludimos a actividades y a acciones de nuestra vida cotidiana mediante las que nos referimos a lugares delimitados y físicos (aula, plaza, restaurantes, etc.) en los que normalmente se desarrollan y que pueden ajustarse a la imagen esquemática de recipiente. Por ello, focalizamos de nuevo una parte del recipiente para referirnos a ese todo que lo configura. Estos lugares constituyen la 'ubicación inicial' del sujeto antes de realizar su desplazamiento a lo largo de una trayectoria.

A este mismo patrón conceptual responden las estructuras de a + infinitivo. En dichas estructuras, no sólo se atenúa la idea de desplazamiento, sino que se focaliza especialmente el desarrollo de una acción:

(33) [...] Sí, salir un rato a tomar café [...] (ALCORE, 2002: 1172).

(34) El peor momento es cada vez que salgo a actuar. [...] (CREA).

En estos casos, tanto el esquema de recipiente como el de trayectoria se debilitan. Lo que realmente focalizamos es la acción expresada por el infinitivo (tomar café, actuar, etc.). Por ello, los infinitivos constituyen nuestro "punto de referencia" que nos conduce a la "zona activa”, es decir, a los lugares a los que implícitamente se refieren.

Otro ejemplo interesante y representativo del esquema conceptual que estoy analizando (la parte por el todo) es el que expongo a continuación:

\section{(35) [...] que nos permite salir de los espacios más cerrados de nuestra mente [...] (CREA).}

En este ejemplo se pone de relieve una parte del cuerpo de la persona (la mente) para hacer referencia a un todo representado, en este caso, por el ser humano. Por otra parte, debo señalar que, junto a la imagen de la parte por el todo, entra en funcionamiento la imagen esquemática de contenedor mediante la que surge la metáfora conceptual LA MENTE ES UN RECIPIENTE, tomada, según Chamizo (1998: 110), del ámbito filosófico. La mente es concep- 
tualizada como un recipiente dotado de una superficie delimitada, como si de un espacio físico se tratase.

\section{Conclusiones}

Los usos no locales del verbo salir pueden justificarse, como se ha comprobado en estas páginas, mediante la proyección de tres imágenes esquemáticas básicas: el esquema de trayectoria, el esquema de recipiente y el esquema parte-todo. Por lo que respecta al esquema de trayectoria, este responde a una proyección de conceptos tomados del ámbito espacial (punto de partida, direccionalidad u orientación inherente, entidad desplazada, ruta o recorrido, meta o destino, etc.) que estructuran y organizan nuestra experiencia física en términos de trayectoria hacia otras entidades abstractas que resultan menos accesibles. De esta manera es posible trazar una trayectoria dinámica y horizontal por la que ciertas entidades humanas o inanimadas se desplazan figurativamente desde un 'punto inicial' a una 'meta' situada al final de la trayectoria (Peña, 2003: 125).

La metáfora de trayectoria puede enriquecerse y ampliarse mediante la actuación de otras imágenes esquemáticas subsidiarias, dando lugar al Ilamado "enriquecimiento esquemático" (Peña, 1998: 423 y 2003: 214). Además de la imagen esquemática de proceso, he destacado, por su gran rendimiento en los ejemplos manejados, la imagen esquemática de fuerza. A su vez, he diferenciado distintos tipos de fuerza, según exista algo que motive el desplazamiento de la figura (“compulsión”) o que imposibilite su desplazamiento ("bloqueo"). Otras veces, en cambio, la figura supera con éxito todos los obstáculos y consigue llegar a su destino ("eliminación de barreras").

En cuanto al esquema de recipiente, la localización inicial de la que parte el sujeto en su desplazamiento figurativo a lo largo de una trayectoria puede ser entendida como un recipiente abierto o cerrado que la figura abandona para dirigirse a un lugar exterior. En el interior de ese recipiente he hallado dos entidades cognitivas básicas: cosas y personas. Si bien en estos casos el recipiente suele estar abierto, permitiendo con ello que la figura pueda desplazarse libremente sin ejercer ningún control sobre ella, en ocasiones, el contenedor puede ofrecer un interior excesivamente limitado para albergar a todas las entidades que contiene. Ese es el motivo que impulsa al sujeto a abandonar la región delimitada por el recipiente, ejerciendo presión sobre él sin destruirlo, aunque llega a desbordarlo. Es entonces cuando entra en funcionamiento la imagen esquemática de exceso.

Finalmente, el esquema conceptual básico parte-todo se proyecta metonímicamente en dos direcciones: el todo por la tarde (focalizamos un todo para comprender su relación con una de sus partes) o la parte por el todo (enfatizamos una parte para entender el todo al que pertenece). En el primer caso, el todo puede referirse explícitamente a un lugar para aludir 
de forma implícita a la actividad desarrollada o también a una entidad animada para señalar una de sus partes. En el segundo caso, lo que se pone de relieve en las estructuras analizadas son actividades y acciones de nuestra vida cotidiana mediante las cuales hacemos referencia implícitamente a los lugares en los que se llevan a cabo.

\section{Bibliografía citada}

Azorín Fernández, Dolores (coord.), 2002: Alicante Corpus Oral del Español (ALCORE), Universidad de Alicante: Edición electrónica en CD-ROM.

Azorín Fernández, Dolores, y Juan Luis Jiménez Ruiz (eds.), 1999: Corpus Oral de la Variedad Juvenil universitaria del español hablado en Alicante (COVJA), Alicante: Instituto de Cultura Juan Gil-Albert.

Barcelona, Antonio (ed.), 2002: Metaphor and metonymy at the crossroads: cognitive approaches, Berlín y Nueva York: Mouton de Gruyter.

Barcelona, Antonio, 2011: "Reviewing the properties of metonymy as a technical construct, with particular attention to the view of metonymy as a prototype category" en Réka Benczes, Antonio Barcelona y Francisco Ruiz de Mendoza Ibañez (eds.): Defining metonymy in cognitive linguistics: towards a consensus view, Amsterdam/Filadelfia: John Benjamins, 7-59.

Barcelona, Antonio, 2012: "La metonimia conceptual” en Iraide IbarretXhe-Antuñano y Javier ValenzUELA (dirs.): Lingüística cognitiva, Barcelona: Anthropos, 123-146.

Boons, Jean-Paul, 1985: "Préliminaires a la classification des verbes locatifs: les compléments de lieu, leurs critères, leurs valeurs aspectuelles", Linguisticae Investigationes 9, 195-267.

Boons, Jean-Paul, 1987: "La notion sémantique de déplacement dans une classification syntaxique des verbes locatifs", Langue Française 76, 5-76.

Chamizo Domínguez, Pedro José, 1998: Metáfora y conocimiento, Universidad de Málaga: Analecta Malacitana, Anejos 16.

Cifuentes Honrubia, José Luis, 1999: Sintaxis y semántica del movimiento: aspectos de gramática cognitiva, Alicante: Instituto de Cultura Juan Gil-Albert.

Cifuentes Honrubia, José Luis, y Jesús Llopis Ganga, 1996: Complemento indirecto y complemento de lugar: estructuras locales de base personal en español, Universidad de Alicante: Secretariado de Publicaciones.

Cifuentes Pérez, Paula, 2004: "Esquemas de imagen y su manifestación en los verbos españoles entrar, salir, meter y sacar", Interlingüística 15, 299-309. 
CRego García, María Victorina, 1996: "Procesos metafóricos y traslaciones funcionales en las estructuras locativas”, Analecta Malacitana 19 (2), 455-468.

Crego García, María Victorina, 2000: El complemento locativo en español: los verbos de movimiento y su combinatoria sintáctico-semántica, Universidad de Santiago de Compostela: Servicio de Publicaciones e Intercambio Científico.

Evans, Vyvyan, y Melanie Green, 2006: Cognitive Linguistics: an introduction, Edimburgo: Edimburgo University Press.

Fornés, Mercedes, y Francisco José Ruiz de MendozA, 1998: "Esquemas de imágenes y construcción del Espacio", RILCE 14 (1), 23-43.

Garcia-Miguel, José María, 1995: Transitividad y complementación preposicional en español, Universidad de Santiago de Compostela: Verba, Anexo 40.

Geeraerts, Dirk, y Hanne CuyCKens, 2007: The Oxford handbook of cognitive linguistics, New York: Oxford University Press.

Horno Chéliz, María del Carmen, 2002: Lo que la preposición esconde: estudio sobre la argumentalidad preposicional en el predicado verbal, Zaragoza: Prensas Universitarias de Zaragoza.

Johnson, Mark, 1987: The body in the mind: the bodily basis of meaning, imagination, and reason, Chicago: University of Chicago Press.

KöveCSEs, Zoltán, 2000: Metaphor and emotion: Ianguage, culture and body in human feeling, Cambridge: Cambridge University Press.

KöveCSES, Zoltán, 2006: Language, mind and culture: a practical introduction, New York: Oxford University Press.

Kövecses, Zoltán, 2010: Metaphor: a practical introduction, New York: Oxford University Press.

LAKOFF, George, 1987: Women, fire and dangerous things, United States of America: University of Chicago Press.

LAKOFF, George, 1989: "Some empirical results about the nature of concepts", Mind \& Language $4(1-2), 103-129$.

Lakoff, George, y Mark Johnson, 1991: Metáforas de la vida cotidiana, Madrid: Cátedra.

Lakoff, George, y Mark Johnson, 1999: Philosophy in the flesh: the embodied mind and its challenge to western thought, New York: Basic Books. 
LAKoff, George, y Mark Turner, 1989: More than Cool Reason: a field guide to poetic metaphor, Chicago: University of Chicago Press.

LAmIRoy, Béatrice, 1987: "Les verbes de mouvement. Emplois figurés et extensions métaphoriques”, Langue Française 26, 41-58.

LAmiRoy, Béatrice, 1991: Léxico y gramática del español: estructuras verbales de espacio y tiempo, Barcelona: Anthropos.

LANGACKER, Ronald Wayne, 1984: "Active zones", Proceedings of the Annual Meeting of the Berkeley Linguistics Society 10, 172-188.

LANGACKER, Ronald Wayne, 1990: Concept, Image, and Symbol: the Cognitive Basis of Grammar, Berlín: Mouton de Gruyter.

LANGACKer, Ronald Wayne, 1993: "Reference-point constructions", Cognitive Linguistics 4, 1-38.

LAUR, Dany, 1993: "La relation entre le verbe et la préposition dans la sémantique du déplacement”, Langages 110, 47-67.

Morera Pérez, Marcial, 1988: Estructura semántica del sistema preposicional del español moderno y sus campos de usos, Puerto del Rosario: Servicio de Publicaciones del Excmo. Cabildo Insular de Fuerteventura.

Morimoto, Yuko, 2001: Los verbos de movimiento, Madrid: Visor Libros.

Peña Cervel, Sandra, 1998: "Towards a new theory of images-schemas: interaction among image-schemas" en José Luis Cifuentes Honrubia (ed.): Estudios de Lingüística Cognitiva I, Alicante: Universidad de Alicante, 417-427.

Peña Cervel, Sandra, 2003: Topology and Cognition: what Image-schemas Reveal about the Metaphorical Language of Emotions, Muenchen: Lincom Europa.

Peña Cervel, Sandra, 2004: "The image-schematic basis of the EVENT STRUCTURE metaphor", Anual Review of Cognitive Linguistics 2, 127-158.

Peña Cervel, Sandra, 2008: "Dependency systems for image-schematic patterns in a usagedbased approach to language", Journal of Pragmátics 40 (6), 1041-1066.

Peña Cervel, Sandra, 2012: "Los esquemas de imagen" en Iraide IbarretXhe-Antuñano y Javier ValenzUELA (dirs.): Lingüística Cognitiva, Barcelona: Anthropos, 69-96.

Peña Cervel, Sandra, y Francisco José Ruiz de Mendoza Ibẫez, 2010: "Los modelos cognitivos idealizados" en Ricardo Mairal Usón, Sandra Peña Cervel, Francisco José Cortés Rodriguez, Francisco José 
Ruiz de Mendoza, María Beatriz Cabello de Alba e Ismael Iván Teomiro García (eds.): Teoría lingüística: métodos, herramientas y paradigmas, Madrid: Ramón Areces, 231-285.

Radulescu Anca, Romana, 2005: “El verbo salir en expresiones metafóricas e idiomáticas”, Interlingüística 16 (2), 891-903.

Real Academia Española: Corpus de Referencia del Español Actual (CREA), [disponible en http://www.rae.es/recursos/banco-de-datos/crea, fecha de consulta: 24 de septiembre de 2016].

SweEtser, Eve, 1990: From Etymology to Pragmatics: metaphorical and cultural aspects of semantic structure, Cambridge: Cambridge University Press.

Talmy, Leonard, 1975: "Semantics and syntax of motion" en John Kimball (ed.): Syntax and Semantics, New York: Academic Press, 181-282.

TALmy, Leonard, 2000: "Force Dynamics in Language and Cognition", Toward a Cognitive Semantics. Concept Structuring Systems. Volume I, Massachusetts: Institute of Technology, 409-470.

TAYLOR, John Robert, 1989: Linguistic Categorization: prototypes in Linguistic Theory, Oxford: Clarendon Press.

Verveckken, Katrien, y Nicole Delbecque, 2007: "Significado esquemático y redes conceptuales de los verbos de trayectoria entrar y salir" en Irene Castellón Masalles y Ana Fernández Montraveta (eds.): Perspectivas de análisis de la unidad verbal SERES, Barcelona: Universidad de Barcelona, $93-111$. 